\title{
BMJ Open Serum 25-hydroxyvitamin D level, chronic diseases and all-cause mortality in a population-based prospective cohort: the HUNT Study, Norway
}

Yi-Qian Sun, ${ }^{1}$ Arnulf Langhammer, ${ }^{2}$ Frank Skorpen, ${ }^{1}$ Yue Chen, ${ }^{3}$ Xiao-Mei Mai $^{2}$

To cite: Sun $Y-Q$, Langhammer A, Skorpen F, et al. Serum 25-hydroxyvitamin D level, chronic diseases and allcause mortality in a populationbased prospective cohort: the HUNT Study, Norway. BMJ Open 2017;7:e017256. doi:10.1136/ bmjopen-2017-017256

- Prepublication history and additional material are available. To view these files please visit the journal online (http://dx.doi. org/10.1136/bmjopen-2017017256).

Received 11 April 2017 Revised 3 May 2017

Accepted 4 May 2017

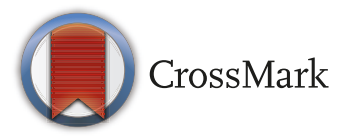

${ }^{1}$ Department of Laboratory Medicine, Children's and Women's Health (LBK), Trondheim, Norway ${ }^{2}$ Department of Public Health and Nursing, Norwegian University of Science and Technology, NTNU, Trondheim, Norway

${ }^{3}$ School of Epidemiology, Public Health and Preventive Medicine, Faculty of Medicine, University of Ottawa, Ottawa, Canada

Correspondence to

Dr Yi-Qian Sun; yi-gian.sun@ ntnu.no

\section{ABSTRACT}

Objective To investigate the association of vitamin D status with all-cause mortality in a Norwegian population and the potential influences of existing chronic diseases on the association.

Design A population-based prospective cohort study. Setting Nord-Trøndelag County, Norway.

Participants A random sample $(n=6613)$ of adults aged 20 years or older in a cohort.

Methods Serum 25-hydroxyvitamin D (25(OH)D) levels were measured in blood samples collected at baseline $(n=6377)$. Mortality was ascertained from the Norwegian National Registry. Cox regression models were applied to estimate the HRs with $95 \%$ Cls for all-cause mortality in association with serum 25(OH)D levels after adjustment for a wide spectrum of confounding factors as well as chronic diseases at baseline.

Results The median follow-up time was 18.5 years, during which 1539 subjects died. The HRs for all-cause mortality associated with the first quartile level of $25(\mathrm{OH})$ $\mathrm{D}(<34.5 \mathrm{nmol} / \mathrm{L})$ as compared with the fourth quartile ( $\geq 58.1 \mathrm{nmol} / \mathrm{L}$ ) before and after adjustment for chronic diseases at baseline were 1.30 (95\% $\mathrm{Cl} 1.11$ to 1.51) and 1.27 (95\% Cl 1.09 to 1.48), respectively. In the subjects without chronic diseases at baseline and with further exclusion of the first 3 years of follow-up, the corresponding adjusted HR was $1.34(95 \% \mathrm{Cl} 1.09$ to 1.66).

Conclusions Low serum 25(OH)D level was associated with increased all-cause mortality in a general Norwegian population. The association was not notably influenced by existing chronic diseases.

\section{INTRODUCTION}

All-cause mortality is an outcome with high public health relevance. Globally, life expectancy in elderly has steadily increased over the past 30 years. ${ }^{1}$ Decline in older age mortality has been mainly the result of decreases in smoking for men and in cardiovascular disease mortality for both genders. ${ }^{1}$ Findings of new risk factors for mortality and subsequent prevention could improve life expectancy further.
Strengths and limitations of this study

Data were from the Nord-Trøndelag Health Study 2 (HUNT2): a large population-based Norwegian cohort with long follow-up time (median 18.5 years).

- The potential influences of existing chronic diseases on the association of serum 25-hydroxyvitamin D levels with all-cause mortality were investigated with two definitions of chronic illness respectively.

- The observed associations remained when the analyses were performed in the subjects without chronic diseases at baseline, and with further exclusion of the first 3 years of follow-up.

- Secondary analyses based on the imputed data for missing values of covariates produced similar association estimates.

- Non-participation in HUNT2 (30\%) may influence the generalisability of our findings.

Vitamin D status has been recognised as a public health issue since low vitamin $\mathrm{D}$ levels are very common and may lead to the development of a wide spectrum of diseases. ${ }^{2-5}$ The pleiotropic effect of vitamin D was suggested by the presence of vitamin $\mathrm{D}$ synthesis enzymes and vitamin $\mathrm{D}$ receptors in many tissues. ${ }^{67}$ In addition, vitamin $\mathrm{D}$ is estimated to regulate $1 \%-3 \%$ of all gene expressions in human. ${ }^{89}$

All latest meta-analyses of epidemiological studies have documented that individuals with low serum 25-hydroxyvitamin D $(25(\mathrm{OH}) \mathrm{D})$ levels are at increased risk of all-cause mortality. ${ }^{5}$ 10-15 Among the meta-analysis studies a few included chronic diseases as potential confounders and found that the association estimates were similar before and after the adjustment for these variables. ${ }^{12}{ }^{13}$ Nevertheless, there has been a growing concern on the possibility of reverse association between low vitamin $\mathrm{D}$ and existing chronic diseases leading to increased all-cause mortality. ${ }^{16}$ Thus, the aim of the current study was to investigate 
the association of serum $25(\mathrm{OH}) \mathrm{D}$ levels with all-cause mortality in a long-term follow-up of a Norwegian population, and to especially study the potential influences of chronic diseases as a possible confounder, effect modifier or reverse causal factor on the relationship between serum $25(\mathrm{OH}) \mathrm{D}$ levels and all-cause mortality.

\section{METHODS}

\section{Study design and population}

The Nord-Trøndelag Health Study (the HUNT Study) is one of the largest population-based health surveys conducted in Norway. The adult part of HUNT invited all inhabitants aged 20 years or older in the county of Nord-Trøndelag in the three separate surveys: HUNT1 (1984-1986), HUNT2 (1995-1997) and HUNT3 (20062008). In the current study, we used data from HUNT2 in which 65229 subjects participated (response rate 70\%). All participants in HUNT2 were invited to complete a general questionnaire including lifestyle questions, social economic status and history of chronic diseases. At the clinical examination, body weight and height were measured and blood samples were drawn for later measurement of biomarkers. We established a subcohort population $(\mathrm{n}=6613)$ including a $10 \%$ random sample of the HUNT2 population. Baseline serum 25(OH)D levels were measured in 6377 individuals whose blood samples were available from HUNT2. The 6377 adults $(96.4 \%$ of the 6613 subjects) made up our analysis cohort.

\section{Measurement of serum 25(OH)D levels}

Blood samples collected in HUNT2 were stored at $-70^{\circ} \mathrm{C}$. Serum $25(\mathrm{OH}) \mathrm{D}$ levels were measured using LIAISON 25-OH Vitamin D TOTAL (DiaSorin, Saluggia, Italy), a fully automated antibody-based chemiluminescence assay. The detection range of the assay is $10-375 \mathrm{nmol} / \mathrm{L}$. The assay has an intra-assay coefficient of variation of $4 \%$ and an interassay coefficient of variation of $8 \%$.

\section{Ascertainment of all-cause mortality}

The HUNT Research Centre receives updated information about deaths of all causes and emigration of the HUNT participants from the Norwegian National Registry. The Norwegian National Registry records the date of death for all people living in Norway. In the current study, the HUNT2 participants were followed up from their participation date until 15 April 2015 or the date of death.

\section{Information on covariates}

Baseline variables were collected by questionnaires or at clinical examination. These covariates were categorised as: age ( $<35,35-44,45-54,55-64,65-74$ and $\geq 75$ years), sex (female, male), season of blood draw (spring: MarchMay, summer: June-August, fall: September-November, winter: December-February), daily smoker (never, former, current), alcohol consumption (never, 1-4 times per month, $\geq 5$ times per month), physical activity (inactive or very low, low, moderate, high), education $(<10,10-12, \geq 13$ years) and economic difficulties (During the last year, has it at any time been difficult to meet the costs of food, transportation, housing and such? yes/no). Body mass index (BMI, $\mathrm{kg} / \mathrm{m}^{2}$ ) was grouped into $<25.0$, 25.0-29.9 and $\geq 30.0 \mathrm{~kg} / \mathrm{m}^{2}$ categories according to the recommendations of the WHO ${ }^{17}$ Chronic illness at baseline (first definition) was a variable generated from responses to a number of questions on major somatic diseases (Have you had or do you have any of the following diseases: myocardial infarction (heart attack)/angina pectoris (chest pain)/stroke (brain haemorrhage)/diabetes/cancer? yes/no). Chronic illness at baseline (second definition) was a direct variable extracted from the HUNT2 questionnaire data (Do you suffer from any long-term illness or injury of a physical or psychological nature that impairs your functioning in your everyday life (long term means at least 1 year)? yes/no). People with missing information on BMI, smoking, alcohol consumption, physical activity, education years, economic difficulties or chronic illness were regarded as an 'unknown' category for each variable and included in the primary analyses. The classification of each covariate has been widely used in the previous HUNT studies. ${ }^{18} 19$

\section{Statistical analyses}

We first tested the linearity of serum $25(\mathrm{OH}) \mathrm{D}$ levels in relation to all-cause mortality using restricted cubic spline model, which showed evidence of departure from a linear relationship $(\mathrm{p}=0.03)$. Therefore, $25(\mathrm{OH}) \mathrm{D}$ levels were treated as a categorical variable classified by quartiles and cut-off points $(<25.0,25.0-49.9,50.0-74.9, \geq 75.0 \mathrm{nmol} / \mathrm{L})$ for presentation of results. The fourth quartile $(\geq 58.1 \mathrm{nmol} / \mathrm{L})$ and the level $50.0-74.9 \mathrm{nmol} / \mathrm{L}$ were used as the reference groups respectively since the level $50.0-74.9 \mathrm{nmol} / \mathrm{L}$ was suggested as sufficient according to the National Academy of Sciences report. ${ }^{20}$

Cox proportional hazards regression models were applied to estimate the HRs with $95 \%$ CIs for all-cause mortality in association with serum $25(\mathrm{OH}) \mathrm{D}$ levels. Person-years were calculated from the date of participation in HUNT2 to the date when death occurred, the person emigrated out of Norway or follow-up ended (15 April 2015), whichever occurred the first. We tested proportional hazards assumption by Schoenfeld residuals for 25(OH)D levels and all covariates. Apart from sex, physical activity and economic difficulties, other variables did not show evidence against proportional hazards assumption. We therefore used the tvc option of the stcox command in Stata to model the non-proportional hazards for sex, physical activity and economic difficulties. Four multivariable models were presented to adjust confounding: model 1 adjusted for season of blood draw since serum $25(\mathrm{OH}) \mathrm{D}$ levels vary by season; model 2 adjusted for age, sex, BMI, smoking, alcohol consumption, physical activity, education and economic difficulties as potential confounders in addition to season of blood draw; model 3 adjusted for chronic illness (first definition) in addition to the variables included in model 2; 
Table 1 Baseline characteristics of subjects in random subcohort and analysis cohort in the HUNT2 study, 19951997

\begin{tabular}{|c|c|c|}
\hline & $\begin{array}{l}\text { Subcohort } \\
(n=6613)\end{array}$ & $\begin{array}{l}\text { Analysis cohor } \\
(n=6377)\end{array}$ \\
\hline \multicolumn{3}{|l|}{ Age (years) } \\
\hline$<65$ & $5028(76.0 \%)$ & $4878(76.5 \%)$ \\
\hline$\geq 65$ & $1585(24.0 \%)$ & $1499(23.5 \%)$ \\
\hline \multicolumn{3}{|l|}{ Sex } \\
\hline Female & $3493(52.8 \%)$ & $3395(53.2 \%)$ \\
\hline Male & $3120(47.2 \%)$ & $2982(46.8 \%)$ \\
\hline \multicolumn{3}{|l|}{ Season of blood draw } \\
\hline Spring & $1523(23.0 \%)$ & $1474(23.1 \%)$ \\
\hline Summer & $828(12.5 \%)$ & $800(12.5 \%)$ \\
\hline Fall & $2303(34.8 \%)$ & 2225 (34.9\%) \\
\hline Winter & 1959 (29.6\%) & $1878(29.4 \%)$ \\
\hline \multicolumn{3}{|l|}{ Body mass index $\left(\mathrm{kg} / \mathrm{m}^{2}\right)$} \\
\hline $\begin{array}{l}\text { Normal/underweight } \\
(<25.0)\end{array}$ & 2637 (39.9\%) & $2558(40.1 \%)$ \\
\hline Overweight (25.0-29.9) & $2822(42.7 \%)$ & $2744(43.0 \%)$ \\
\hline Obese $(\geq 30.0)$ & $1064(16.1 \%)$ & $1022(16.0 \%)$ \\
\hline Unknown & $90(1.4 \%)$ & $53(0.8 \%)$ \\
\hline \multicolumn{3}{|l|}{ Daily smoker } \\
\hline Never & $2798(42.3 \%)$ & $2720(42.7 \%)$ \\
\hline Former & $1752(26.5 \%)$ & $1688(26.5 \%)$ \\
\hline Current & $1896(28.7 \%)$ & $1822(28.6 \%)$ \\
\hline Unknown & $167(2.5 \%)$ & $147(2.3 \%)$ \\
\hline \multicolumn{3}{|c|}{ Alcohol consumption (times per month) } \\
\hline Never & $2295(34.7 \%)$ & $2190(34.3 \%)$ \\
\hline $1-4$ & $3010(45.5 \%)$ & $2937(46.1 \%)$ \\
\hline$\geq 5$ & $726(11.0 \%)$ & $704(11.0 \%)$ \\
\hline Unknown & $582(8.8 \%)$ & $546(8.6 \%)$ \\
\hline \multicolumn{3}{|l|}{ Physical activity } \\
\hline Inactive or very low & $1419(21.5 \%)$ & $1367(21.4 \%)$ \\
\hline Low & $1155(17.5 \%)$ & $1121(17.6 \%)$ \\
\hline Moderate & $1424(21.5 \%)$ & $1378(21.6 \%)$ \\
\hline High & $557(8.4 \%)$ & $544(8.5 \%)$ \\
\hline Unknown & 2058 (31.1\%) & 1967 (30.8\%) \\
\hline \multicolumn{3}{|l|}{ Education (years) } \\
\hline$<10$ & $2271(34.3 \%)$ & $2180(34.2 \%)$ \\
\hline $10-12$ & $2150(32.5 \%)$ & 2085 (32.7\%) \\
\hline$\geq 13$ & $1824(27.6 \%)$ & $1774(27.8 \%)$ \\
\hline Unknown & $368(5.6 \%)$ & $338(5.3 \%)$ \\
\hline \multicolumn{3}{|l|}{ Economic difficulties } \\
\hline No & $3197(48.3 \%)$ & 3125 (49.0\%) \\
\hline Yes & $1351(20.4 \%)$ & $1304(20.4 \%)$ \\
\hline Unknown & 2065 (31.2\%) & $1948(30.5 \%)$ \\
\hline
\end{tabular}

Continued
Table 1 Continued

\begin{tabular}{|c|c|c|}
\hline & $\begin{array}{l}\text { Subcohort } \\
(n=6613)\end{array}$ & $\begin{array}{l}\text { Analysis cohort } \\
(n=6377)\end{array}$ \\
\hline No & $5418(81.9 \%)$ & $5256(82.4 \%)$ \\
\hline Yes & $906(13.7 \%)$ & $856(13.4 \%)$ \\
\hline Unknown & $289(4.4 \%)$ & $265(4.2 \%)$ \\
\hline \multicolumn{3}{|c|}{ Chronic illness (second definition) } \\
\hline No & $4115(62.2 \%)$ & $4007(62.8 \%)$ \\
\hline Yes & $2228(33.7 \%)$ & $2125(33.3 \%)$ \\
\hline Unknown & $270(4.1 \%)$ & $245(3.8 \%)$ \\
\hline
\end{tabular}

Data are given as number of subjects (percentage).

HUNT2, the Nord-Trøndelag Health Study 2.

model 4 adjusted for chronic illness (second definition) in addition to the variables in model 2.

To address the issue of potential effect modification by existing chronic diseases, the association of serum $25(\mathrm{OH}) \mathrm{D}$ levels with all-cause mortality was evaluated in subgroups stratified by chronic illness (first and second definitions). To further address possible reverse association, we restricted the analyses to subjects without chronic diseases at baseline, and with additional exclusion of the first 3 years of follow-up.

For secondary analyses, based on assumption of missing at random, missing values ('unknown' in tables 1 and 2) in covariates BMI, daily smoker, alcohol consumption, physical activity, education, economic difficulties and chronic illness (first and second definitions) were imputed using multivariable chained imputation with fully conditional specification (command mi impute chained in Stata). Cox proportional hazards regression was executed on 10 imputed datasets to obtain 10 sets of coefficients and SEs, and the averaged estimates were given as inferential statistics.

All statistical analyses were performed with Stata/SE V.13.1 (College Station, Texas, USA).

\section{RESULTS}

Table 1 shows that the analysis cohort $(n=6377)$ and the random subcohort $(\mathrm{n}=6613)$ had similar distributions of the covariates. The median follow-up time among the 6377 adults was 18.5 years, and during the study period 1539 subjects died and 26 emigrated out of the country.

As shown in table 2, the mean level of serum $25(\mathrm{OH})$ $\mathrm{D}$ in the analysis cohort was $47.3 \mathrm{nmol} / \mathrm{L}$, with a lower level in the subjects with chronic illness (first definition) than those without chronic illness $(45.2$ vs $47.8 \mathrm{nmol} / \mathrm{L}$ respectively, $\mathrm{p}<0.001)$. In both the total cohort and the subgroup without chronic illness, multiple linear regression analysis revealed that older age, summer or fall season, more frequent alcohol consumption and higher level of physical activity were associated with higher $25(\mathrm{OH}) \mathrm{D}$ levels, whereas people with high BMI, current smoking and socioeconomic difficulties had lower levels 
Table 2 Overall and chronic illness-stratified distributions of serum 25(OH)D level according to baseline covariates 25(OH)D level (nmol/L)

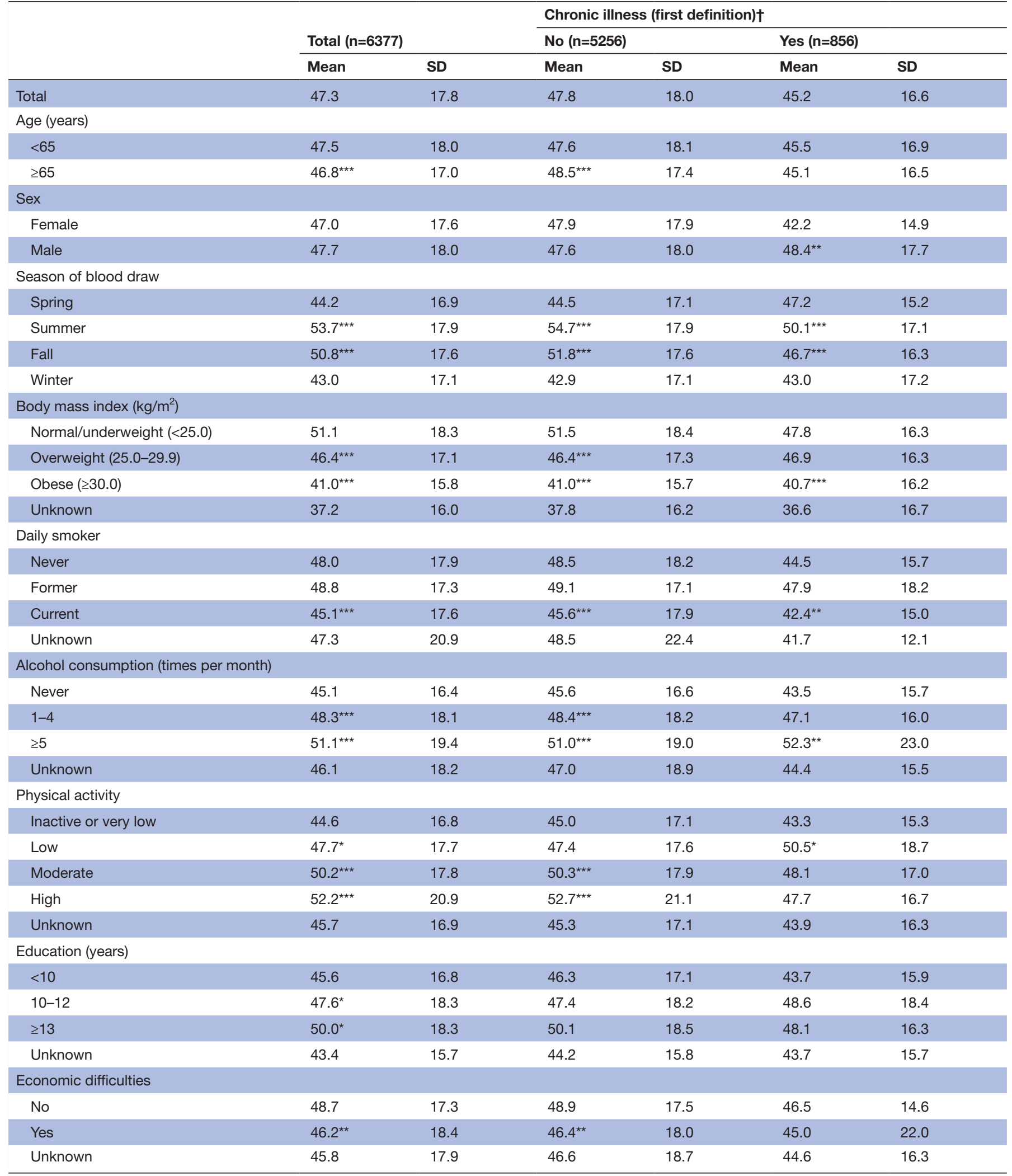

Multiple linear regression analysis was used to compare the mean levels of $25(\mathrm{OH}) \mathrm{D}$ with the first category (reference) for each baseline covariate. ${ }^{*} \mathrm{p}<0.05 ;{ }^{* \star} \mathrm{p}<0.01 ;{ }^{* \star *} \mathrm{p}<0.001$.

†265 subjects with missing information on chronic illness (first definition) at baseline were excluded.

25(OH)D, 25-hydroxyvitamin D. 


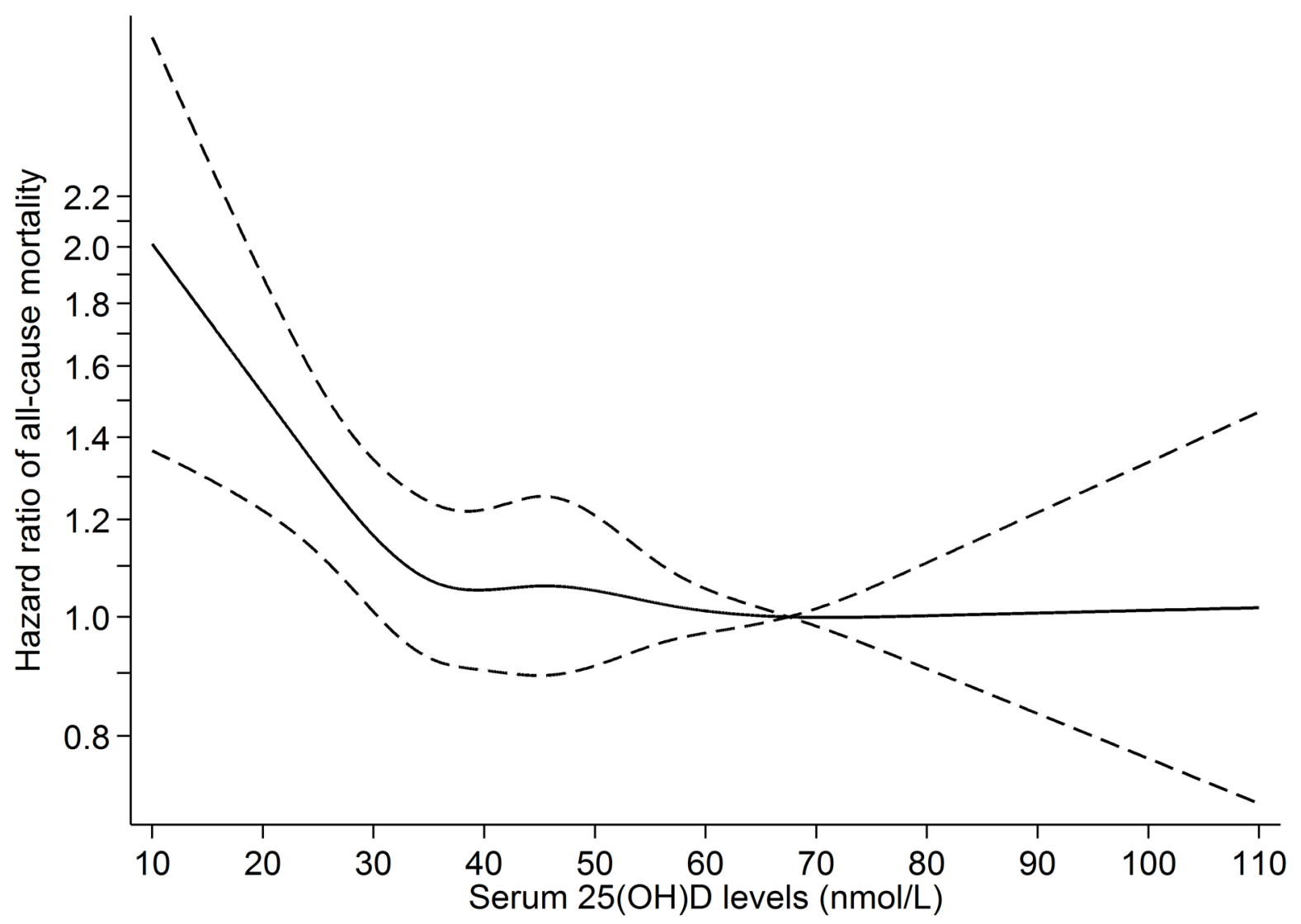

Figure 1 HR of all-cause mortality in association with continuous 25(OH)D levels by restricted cubic spline Cox regression analysis with five knots. Estimates were adjusted for season of blood draw, age, sex, body mass index, smoking, alcohol consumption, physical activity, education and economic difficulties, with $67.5 \mathrm{nmol} / \mathrm{L}$ as the reference value (median of the fourth quartile). 95\% Cls are shown by dashed lines. 25(OH)D, 25-hydroxyvitamin D.

of $25(\mathrm{OH}) \mathrm{D}$. In the subjects with chronic illness, high BMI and current smoking remained to be associated with lower $25(\mathrm{OH}) \mathrm{D}$ levels, while male sex, summer or fall season and more frequent alcohol consumption were associated with higher levels of $25(\mathrm{OH}) \mathrm{D}$.

A non-linear association between serum 25(OH)D level and all-cause mortality was observed using restricted cubic spline Cox regression analysis (figure 1). It appeared that the mortality was minimised when the range of $25(\mathrm{OH})$ $\mathrm{D}$ was $60-100 \mathrm{nmol} / \mathrm{L}$. There was a steady increase in the risk of death when $25(\mathrm{OH}) \mathrm{D}$ level was lower than $35 \mathrm{nmol} / \mathrm{L}$ (figure 1 and table 3 ).

Table 3 presents the HRs and 95\% CIs for all-cause mortality in association with serum $25(\mathrm{OH}) \mathrm{D}$ levels by quartiles and cut-off points categories. In model 2, subjects with $25(\mathrm{OH}) \mathrm{D}$ in the first quartile $(<34.5 \mathrm{nmol} / \mathrm{L})$ showed an HR of 1.30 (95\% CI 1.11 to 1.51) compared with those in the fourth quartile $(\geq 58.1 \mathrm{nmol} / \mathrm{L})$, while subjects with $25(\mathrm{OH}) \mathrm{D}<25.0 \mathrm{nmol} / \mathrm{L}$ showed an HR of $1.45(95 \% \mathrm{CI}$ 1.18 to 1.78$)$ compared with those with $25(\mathrm{OH}) \mathrm{D}$ of 50.0 $74.9 \mathrm{nmol} / \mathrm{L}$. After adjustment for chronic illness (first definition) in model 3, HRs for the first quartile level and $25(\mathrm{OH}) \mathrm{D}<25.0 \mathrm{nmol} / \mathrm{L}$ changed to 1.27 and 1.41 , respectively. After adjustment for chronic illness (second definition) in model 4, the corresponding HRs were slightly changed ( 1.30 and 1.46 , respectively). In addition to the covariates in model 3, we further included systolic and diastolic blood pressures, and serum levels of total cholesterol, high-density lipoprotein and triglycerides, significant associations remained with HRs being 1.24 (95\% CI 1.06 to 1.46) for the first quartile level and 1.38 (95\% CI 1.12 to 1.71 ) for $25(\mathrm{OH}) \mathrm{D}$ level $<25.0 \mathrm{nmol} / \mathrm{L}$.

To address the possible effect modification by chronic diseases, we evaluated the association of serum $25(\mathrm{OH}) \mathrm{D}$ levels with all-cause mortality stratified by chronic illness at baseline (table 4). The HRs for all-cause mortality associated with the first quartile level were 1.32 in the subjects without chronic illness (first definition) and 1.35 in those with chronic illness, and the corresponding HRs associated with $25(\mathrm{OH}) \mathrm{D}<25.0 \mathrm{nmol} / \mathrm{L}$ were 1.24 and 1.63 , respectively. Stratification by chronic illness (second definition) only showed significant associations in the group with chronic diseases. However, likelihood ratio tests did not provide evidence for any effect modification by chronic illness ( $p>0.28$ for all).

Finally, to further address potential reverse association, we restricted our analyses to subjects without chronic illness (first definition) and with further exclusion of the 


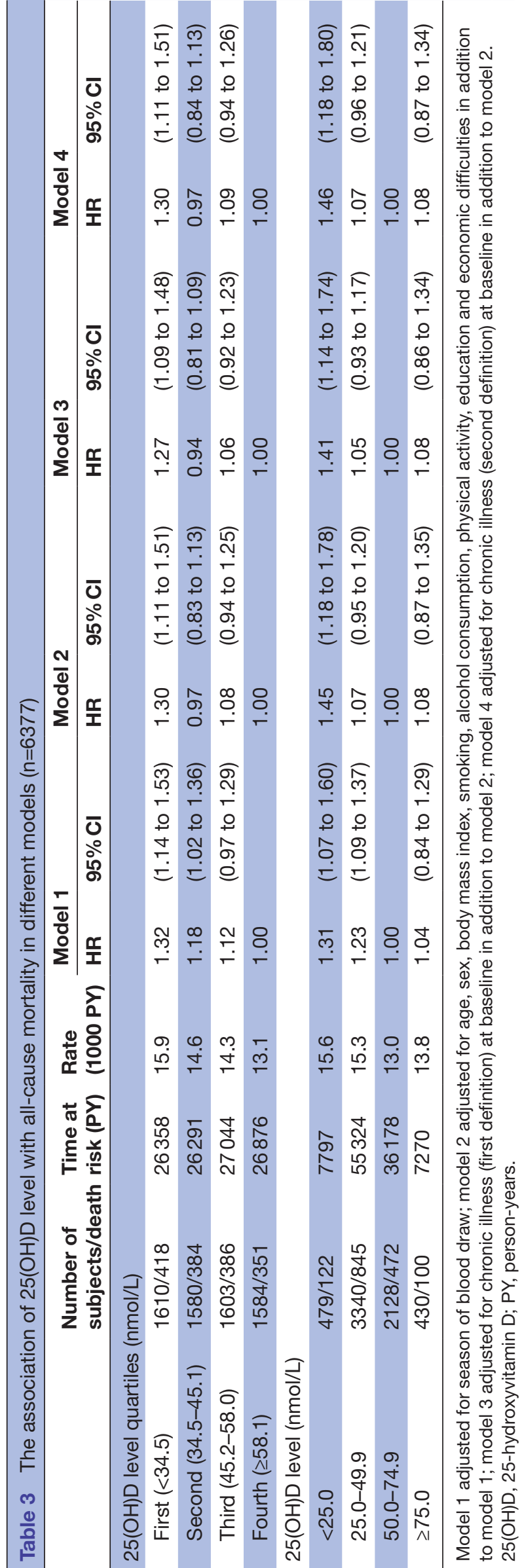

first 3 years of follow-up (table 5). The first quartile level of serum $25(\mathrm{OH}) \mathrm{D}$ was associated with a $34 \%$ increased risk of all-cause mortality compared with the highest quartile level. Subjects with $25(\mathrm{OH}) \mathrm{D}$ level $<25.0 \mathrm{nmol} / \mathrm{L}$ had a $29 \%$ increased risk of all-cause mortality compared with those with level of $50.0-74.9 \mathrm{nmol} / \mathrm{L}$.

In line with the primary analyses, secondary analyses based on the imputed data for missing values of covariates including chronic illness at baseline produced similar results (see online supplementary tables $1-3$ ).

\section{DISCUSSION \\ Main findings}

In this prospective study of 6377 subjects with a median follow-up period of 18.5 years, we found that the lowest $25(\mathrm{OH}) \mathrm{D}$ quartile level $(<34.5 \mathrm{nmol} / \mathrm{L})$ had a $30 \%$ increased risk of all-cause mortality compared with the fourth quartile $(\geq 58.1 \mathrm{nmol} / \mathrm{L})$ before adjustment for chronic illness at baseline. The subjects with $25(\mathrm{OH})$ $\mathrm{D}<25.0 \mathrm{nmol} / \mathrm{L}$ had a $45 \%$ increase in all-cause mortality compared with those with $25(\mathrm{OH}) \mathrm{D}$ of $50.0-74.9 \mathrm{nmol} / \mathrm{L}$. The associations were not significantly confounded or modified by chronic diseases at baseline.

\section{Comparison with other studies}

Our findings of the association of $25(\mathrm{OH}) \mathrm{D}$ with all-cause mortality concurred with those of the meta-analysis studies.$^{5}{ }^{10-15}$ For the non-linear association between serum $25(\mathrm{OH}) \mathrm{D}$ level and all-cause mortality (figure 1 ), the range of $25(\mathrm{OH}) \mathrm{D}$ for the lowest mortality in our study was similar to that in a meta-analysis study using individual participant data and standardised vitamin D levels. ${ }^{13}$ The cut-off level of $25(\mathrm{OH}) \mathrm{D}$ for a steady increase in the risk of mortality was $35 \mathrm{nmol} / \mathrm{L}$ in our study, while it was around $40 \mathrm{nmol} / \mathrm{L}$ in this meta-analysis ${ }^{13}$. Compared with the $45 \%$ increased risk of all-cause mortality associated with $25(\mathrm{OH}) \mathrm{D}$ level $<25 \mathrm{nmol} / \mathrm{L}$ observed in our study, a meta-analysis showed a $90 \%$ increased risk in association with $25(\mathrm{OH}) \mathrm{D}$ level $<25 \mathrm{nmol} / \mathrm{L}$ after adjustment for age only. ${ }^{11}$ Another meta-analysis study showed a $50 \%$ increased risk of all-cause mortality in subjects with $25(\mathrm{OH})$ D level $<25 \mathrm{nmol} / \mathrm{L}{ }^{5}$

Our findings of an increased risk of all-cause mortality associated with low $25(\mathrm{OH}) \mathrm{D}$ levels were not substantially affected by having chronic diseases at baseline. This observation complies with a previous study in which no major changes in the association measures were reported after controlling for histories of chronic diseases. ${ }^{21}$ Two meta-analysis studies including individual participant data came to the same conclusion that additional adjustment for a history of chronic diseases did not alter the association of low vitamin D with increased mortality. ${ }^{12}{ }^{13}$ Chronic diseases included in the aforementioned studies were similar to the ones in our study, namely cardiovascular disease, diabetes and cancer. ${ }^{12}{ }^{13}{ }^{21}$ We also observed a similar association of low $25(\mathrm{OH}) \mathrm{D}$ levels with all-cause mortality in individuals with or without chronic illness 
Table 4 The association of 25(OH)D level with all-cause mortality stratified by chronic illness in model 2

\section{5(OH)D nmol/L quartiles first versus fourth} (reference)

25(OH)D nmol/L <25.0 vs 50.0-74.9 (reference)

$\begin{array}{lllll}\text { HR } & 95 \% \mathrm{Cl} & \mathrm{p} \text { for interaction HR } & 95 \% \mathrm{Cl} & \mathrm{p} \text { for interaction }\end{array}$

\begin{tabular}{|c|c|c|c|c|c|c|}
\hline \multicolumn{3}{|c|}{ Chronic illness (first definition)* } & \multicolumn{3}{|l|}{0.91} & \multirow[t]{2}{*}{0.59} \\
\hline No $(n=5256)$ & 1.32 & (1.08 to 1.62$)$ & & 1.24 & (0.92 to 1.67$)$ & \\
\hline Yes $(n=856)$ & 1.35 & (1.04 to 1.75$)$ & & 1.63 & (1.17 to 2.28$)$ & \\
\hline No $(n=4007)$ & 1.12 & (0.86 to 1.46$)$ & & 1.05 & (0.70 to 1.56$)$ & \\
\hline Yes $(n=2125)$ & 1.36 & (1.12 to 1.66$)$ & & 1.58 & (1.21 to 2.05$)$ & \\
\hline
\end{tabular}

Model 2 adjusted for season of blood draw, age, sex, body mass index, smoking, alcohol consumption, physical activity, education and economic difficulties.

*265 subjects with missing information on chronic illness (first definition) at baseline were excluded.

†245 subjects with missing information on chronic illness (second definition) at baseline were excluded.

25(OH)D, 25-hydroxyvitamin D.

using two different definitions. A previous research reported stronger associations in subjects without cardiovascular disease, diabetes or hypertension than those with these chronic diseases. ${ }^{22}$

\section{Possible mechanisms}

The association between low 25(OH) levels and increased all-cause mortality can be explained by several possible mechanisms. First, vitamin D synthesis enzymes and vitamin $\mathrm{D}$ receptors are present in many tissues, implying a major role of vitamin $\mathrm{D}$ in many physiological and pathological processes. ${ }^{67}$ Second, vitamin D has an important role in the regulation of proliferation, apoptosis and differentiation in many cell types, as well as functions of the immune system. ${ }^{8}{ }^{23}$ Third, epidemiological studies have suggested low vitamin $\mathrm{D}$ level as a risk factor for a wide range of diseases from hip fractures to cardiovascular disease and cancers. $^{3-5}$

Recent research has attempted to study if there is a causal relationship between low vitamin $\mathrm{D}$ and all-cause mortality. A meta-analysis of Mendelian randomisation using four genetic variants around DHCR7 and CYP2R1 as instrumental variables suggested a causal effect of low levels of vitamin D on high all-cause mortality. ${ }^{10}$ In two meta-analysis studies of randomised controlled trials of relative small sample sizes, vitamin $\mathrm{D}_{3}$ supplementation reduced all-cause mortality by $6 \%-11 \%$ in elderly people. $^{524}$ Results from ongoing large clinical trials ${ }^{25} 26$ are awaited to clarify the causal association of vitamin D with mortality, particularly in those with low vitamin D status prior to intervention.

\section{Strengths and limitations}

Selection bias seems not a big issue in our study since the analysis cohort is very similar to the subcohort of a random sample. However, non-participation in the later HUNT3 study was associated with lower socioeconomic status and higher mortality. ${ }^{27}$ Non-participation in HUNT2 presented similar problems but to a less extent, which may influence the generalisability of our findings.

Table 5 The association of 25(OH)D level with all-cause mortality in subjects without chronic illness (first definition) in model 2 , with further exclusion of the first 3 years of follow-up $(n=5184)$

\begin{tabular}{|c|c|c|c|c|c|}
\hline & Number of subjects/death & Time at risk (PY) & Rate (1000 PY) & HR & $95 \% \mathrm{Cl}$ \\
\hline First $(<34.5)$ & $1280 / 199$ & 18674 & 10.7 & 1.34 & (1.09 to 1.66$)$ \\
\hline Third (45.2-58.0) & $1310 / 211$ & 19388 & 10.9 & 1.11 & (0.91 to 1.36$)$ \\
\hline Fourth $(\geq 58.1)$ & $1333 / 198$ & 19732 & 10.0 & 1.00 & \\
\hline \multicolumn{6}{|l|}{ 25(OH)D level (nmol/L) } \\
\hline$<25.0$ & $381 / 51$ & 5607 & 9.1 & 1.29 & (0.95 to 1.76$)$ \\
\hline $25.0-49.9$ & $2663 / 416$ & 39136 & 10.6 & 1.05 & (0.90 to 1.24$)$ \\
\hline $50.0-74.9$ & $1778 / 266$ & 26372 & 10.1 & 1.00 & \\
\hline$\geq 75.0$ & $362 / 55$ & 5339 & 10.3 & 1.04 & (0.77 to 1.40$)$ \\
\hline
\end{tabular}

Model 2 adjusted for season of blood draw, age, sex, body mass index, smoking, alcohol consumption, physical activity, education and economic difficulties.

25(OH)D, 25-hydroxyvitamin D; PY, person-years. 
Serum 25(OH)D provides the most proper assessment of vitamin D status due to its longer half-life time and higher concentrations compared with the physiologically active metabolite 1,25-dihydroxyvitamin D. ${ }^{28}$ One would argue that the one-time measurement of $25(\mathrm{OH}) \mathrm{D}$ level at baseline may not reflect long-term exposure of low vitamin D. Previous studies including a Norwegian study showed that $25(\mathrm{OH}) \mathrm{D}$ concentrations were rather stable up to 14 years of follow-up. ${ }^{29}{ }^{30} \mathrm{In}$ addition, any misclassification of vitamin $\mathrm{D}$ due to measurement error would be non-differential as blood samples had been collected before the events occurred. Liaison immunoassay method tends to underestimate the true $25(\mathrm{OH}) \mathrm{D}$ levels. ${ }^{31}$ Thus, caution is warranted when our results are compared with studies using other assay methods or standardised 25(OH)D levels. ${ }^{132}$ Information about all-cause death of the Norwegian population is recorded and updated continuously at the Norwegian National Registry. The information is complete and accurate and therefore misclassification is unlikely. ${ }^{33}$

A wide spectrum of potential confounders including chronic diseases was adjusted in the current study. Chronic diseases, on one hand, may lead to both low vitamin D levels and increased mortality. ${ }^{34}$ On the other hand, low vitamin D levels may lead to development of chronic diseases and subsequently increased mortality. Thus, chronic diseases may be either potential confounders or mediators in the causal pathway between low 25( $\mathrm{OH}) \mathrm{D}$ status and all-cause mortality. No matter chronic diseases serve as a confounder or mediator, additional adjustment for this variable in model 3 and model 4 did not alter the association of $25(\mathrm{OH})$ D levels with all-cause mortality substantially. However, overadjustment may be possible if chronic diseases were in the pathway. Neither did we find significant effect modification by chronic illness defined by two definitions. Possibility of reverse association between low vitamin $\mathrm{D}$ and chronic diseases has been a main concern in the assessment of the vitamin $\mathrm{D}$ and mortality association. ${ }^{16}$ Nevertheless, the association remained when we restricted the analysis in the subjects without chronic diseases at baseline and with further exclusion of the first 3 years of follow-up. In agreement with a previous study, ${ }^{35}$ our results suggest that low vitamin D level is an important risk factor for all-cause mortality independent of ill health at baseline.

Apart from the limitations, our study is among the few to highlight and thoroughly investigate the potential influences of chronic diseases on the association of low vitamin $\mathrm{D}$ with all-cause mortality.

\section{Conclusions}

Overall, we found that low serum $25(\mathrm{OH}) \mathrm{D}$ level was associated with an increased risk of all-cause mortality in a general Norwegian population. The association was not notably influenced by existing chronic diseases. Results from the ongoing large clinical trials are being awaited to clarify a causal relationship.
Acknowledgements The Nord-Trøndelag Health Study (HUNT) is a collaboration between the HUNT Research Centre (Faculty of Medicine and Health Sciences, NTNU, Norwegian University of Science and Technology), the Nord-Trøndelag County Council and the Norwegian Institute of Public Health. The authors especially thank the HUNT Research Centre laboratory personnel for the measurement of serum $25(\mathrm{OH}) \mathrm{D}$ levels.

Contributors YQS, AL, YC and XMM contributed to the study design. XMM and $A L$ contributed to data collection. YQS conducted statistical analyses, interpreted results and wrote the initial draft of the manuscript. AL, FS, YC and XMM participated in the data interpretation and helped write the final draft of the manuscript.

Funding This work (the research position of YQS) was supported by funding from The Norwegian Cancer Society (project ID 5769155-2015) and The Research Council of Norway ‘Gaveforsterkning'.

Competing interests None declared.

Patient consent All participants gave their informed consent on participation in HUNT, linkage to previous HUNT surveys and specific registries.

Ethics approval The study was approved by the Norwegian Regional Committees for Medical and Health Research Ethics.

Provenance and peer review Not commissioned; externally peer reviewed. Data sharing statement No additional data available.

Open Access This is an Open Access article distributed in accordance with the Creative Commons Attribution Non Commercial (CC BY-NC 4.0) license, which permits others to distribute, remix, adapt, build upon this work non-commercially, and license their derivative works on different terms, provided the original work is properly cited and the use is non-commercial. See: http://creativecommons.org/ licenses/by-nc/4.0/

(C) Article author(s) (or their employer(s) unless otherwise stated in the text of the article) 2017. All rights reserved. No commercial use is permitted unless otherwise expressly granted.

\section{REFERENCES}

1. Mathers CD, Stevens GA, Boerma T, et al. Causes of international increases in older age life expectancy. Lancet 2015;385:540-8.

2. Palacios $C$, Gonzalez L. Is vitamin D deficiency a Major global public health problem? J Steroid Biochem Mol Biol 2014;144:138-45.

3. de Boer IH, Levin G, Robinson-Cohen C, et al. Serum 25-hydroxyvitamin D concentration and risk for Major clinical disease events in a community-based population of older adults: a cohort study. Ann Intern Med 2012;156:627-34.

4. Wang TJ, Vitamin D, Disease CAnnu Rev Med 2016;67:261-72.

5. Chowdhury R, Kunutsor S, Vitezova A, et al. Vitamin D and risk of cause specific death: systematic review and meta-analysis of observational cohort and randomised intervention studies: BMJ (Clinical research ed) 2104, 1903.

6. Uhlén M, Fagerberg L, Hallström BM, et al. Proteomics. Tissuebased map of the human proteome. Science 2015;347:1260419.

7. Uhlen M, Oksvold P, Fagerberg L, et al. Towards a knowledge-based human protein Atlas. Nat Biotechnol 2010;28:1248-50.

8. Holick MF. Vitamin D deficiency. N Engl J Med 2007;357:266-81.

9. Ramagopalan SV, Heger A, Berlanga AJ, et al. A ChIP-seq defined genome-wide map of vitamin $D$ receptor binding: associations with disease and evolution. Genome Res 2010;20:1352-60.

10. Afzal S, Brøndum-Jacobsen P, Bojesen SE, et al. Genetically low vitamin $D$ concentrations and increased mortality: mendelian randomisation analysis in three large cohorts. BMJ 2014;349:g6330.

11. Garland CF, Kim JJ, Mohr SB, et al. Meta-analysis of all-cause mortality according to serum 25-hydroxyvitamin D. Am J Public Health 2014;104:e43-e50.

12. Schöttker B, Jorde R, Peasey A, et al. Vitamin D and mortality: meta-analysis of individual participant data from a large consortium of cohort studies from Europe and the United States. BMJ 2014;348:g3656.

13. Gaksch M, Jorde R, Grimnes G, et al. Vitamin D and mortality: individual participant data meta-analysis of standardized 25-hydroxyvitamin D in 26916 individuals from a european consortium. PLoS One 2017;12:e0170791.

14. Schöttker B, Ball D, Gellert C, et al. Serum 25-hydroxyvitamin D levels and overall mortality. A systematic review and meta-analysis of prospective cohort studies. Ageing Res Rev 2013;12:708-18. 
15. Zittermann A, lodice S, Pilz S, et al. Vitamin D deficiency and mortality risk in the general population: a meta-analysis of prospective cohort studies. Am J Clin Nutr 2012;95:91-100.

16. Autier $\mathrm{P}$, Boniol M, Pizot $\mathrm{C}$, et al. Vitamin $\mathrm{D}$ status and ill health: a systematic review. Lancet Diabetes Endocrinol 2014;2:76-89.

17. Obesity: preventing and managing the global epidemic. Report of a WHO consultation. World Health Organ Tech Rep Ser 2000;894253:1.

18. Brumpton BM, Langhammer A, Ferreira MA, et al. Physical activity and incident asthma in adults: the HUNT Study, Norway. BMJ Open 2016;6:e013856.

19. Mai XM, Langhammer A, Chen Y, et al. Cod liver oil intake and incidence of asthma in norwegian adults--the HUNT study. Thorax 2013;68:25-30.

20. Ross AC, Taylor CL, Yaktine AL, et al; Dietary Reference Intakes for calcium and vitamin D. Washington, DC: The National Academies Press, 2011 ..

21. Ford ES, Zhao G, Tsai J, et al. Vitamin D and all-cause mortality among adults in USA: findings from the National Health and Nutrition Examination Survey Linked Mortality Study. Int J Epidemiol 2011;40:998-1005.

22. Melamed ML, Michos ED, Post W, et al. 25-hydroxyvitamin D levels and the risk of mortality in the general population. Arch Intern Med 2008;168:1629-37.

23. Feldman D, Krishnan AV, Swami S, et al. The role of vitamin $D$ in reducing Cancer risk and progression. Nat Rev Cancer 2014;14:342-57.

24. Bjelakovic G, Gluud LL, Nikolova D, et al; Vitamin D supplementation for prevention of mortality in adults. : The Cochrane database of systematic reviews, 2014:Cd007470. (published Online First: 15 Jan 2015)

25. Kupferschmidt K. Uncertain verdict as vitamin D Goes on trial. Science 2012;337:1476-8.
26. Pilz S, Rutters F, Dekker JM. Disease prevention: vitamin D trials. Science 2012;338:883.

27. Langhammer A, Krokstad S, Romundstad P, et al. The HUNT study: participation is associated with survival and depends on socioeconomic status, diseases and symptoms. BMC Med Res Methodol 2012;12:143.

28. Zerwekh JE. Blood biomarkers of vitamin D status. Am J Clin Nutr 2008;87:1087s-91.

29. Jorde R, Sneve M, Hutchinson M, et al. Tracking of serum 25-hydroxyvitamin D levels during 14 years in a population-based study and during 12 months in an intervention study. Am J Epidemiol 2010;171:903-8.

30. Schöttker B, Haug U, Schomburg L, et al. Strong associations of 25-hydroxyvitamin D concentrations with all-cause, cardiovascular, Cancer, and respiratory disease mortality in a large cohort study. Am J Clin Nutr 2013;97:782-93.

31. Schöttker B, Jansen EH, Haug U, et al. Standardization of misleading immunoassay based 25-hydroxyvitamin D levels with liquid chromatography andem-mass spectrometry in a large cohort study. PLoS One 2012;7:e48774.

32. Binkley N, Sempos CT; Vitamin D Standardization Program (VDSP). Standardizing vitamin D assays: the way forward. J Bone Miner Res 2014;29:1709-14.

33. Norwegian National Registry 2017. http://www.skatteetaten.no/en/ person/National-Registry/ (cited 19 Nov 2016).

34. Autier P. Vitamin D status as a synthetic biomarker of health status. Endocrine 2016;51:201-2.

35. Schöttker B, Saum KU, Perna L, et al. Is vitamin D deficiency a cause of increased morbidity and mortality at older age or simply an Indicator of poor health? Eur J Epidemiol 2014;29:199-210. 